\title{
Correction to: Vaccination with nanoparticles combined with micro-adjuvants protects against cancer
}

\author{
Mona O. Mohsen ${ }^{1,2,11^{*}}$, Matthew D. Heath ${ }^{3}$, Gustavo Cabral-Miranda ${ }^{2}$, Cyrill Lipp ${ }^{2}$, Andris Zeltins ${ }^{4}$, Marcos Sande ${ }^{5}$, \\ Jens V. Stein ${ }^{6}$, Carsten Riether ${ }^{7}$, Elisa Roesti ${ }^{2}$, Lisha Zha ${ }^{2,8}$, Paul Engeroff ${ }^{2}$, Aadil El-Turabi ${ }^{1}$, Thomas M. Kundig ${ }^{9}$, \\ Monique Vogel ${ }^{2}$, Murray A. Skinner ${ }^{3}$, Daniel E. Speiser ${ }^{10}$, Alexander Knuth ${ }^{11}$, Matthias F. Kramer ${ }^{3}$ and \\ Martin F. Bachmann ${ }^{1,2}$
}

\section{Correction to: J ImmunoTherapy Cancer https://doi.org/10.1186/s40425-019-0587-z}

Following publication of the original article [1], the authors reported an author's family name has been erroneously spelled. Paul Engroff should be replaced Paul Engeroff.

Furthermore, there are two errors in the following affiliations: 9) Department of dermatology, University of Zurich, Bern, Switzerland and 10) Department of Oncology, University of Lausanne, Bern,Switzerland should be replaced with 9) Department of dermatology, University of Zurich, Zurich, Switzerland and 10) Department of Oncology, University of Lausanne, Lausanne, Switzerland.

The corrections have been implemented in the original article as well.

The publisher apologized for any inconvenience this might has caused.

\footnotetext{
Author details

${ }^{1}$ Jenner Institute, Nuffield Department of Medicine, University of Oxford, Oxford, UK. ²Department of BioMedical Research, Immunology RIA, Inselspital, University of Bern, Bern, Switzerland. ${ }^{3}$ Bencard Adjuvant Systems, Dominion Way, Worthing, UK. ${ }^{4}$ Latvian Biomedical Research \& Study Centre, Riga, Latvia. ${ }^{5}$ Institute of anatomy, University of Bern, Bern, Switzerland.

${ }^{6}$ Theodor Kocher Institute, University of Bern, Bern, Switzerland. ${ }^{7}$ Department of Medical Oncology, Bern University Hospital, University of Bern, Bern, Switzerland. ${ }^{8}$ International Immunology Center, Anhui Agricultural University, Hefei, Anhui, China. ${ }^{9}$ Department of Dermatology, University of Zurich, Zurich, Switzerland. ${ }^{10}$ Department of Oncology, University of Lausanne, Lausanne, Switzerland. ${ }^{11}$ National Center for Cancer Care \& Research (NCCCR), Doha, State of Qatar.

*Correspondence: Mona.mohsen@dbmr.unibe.ch; Monamona20@icloud.com ${ }^{1}$ Jenner Institute, Nuffield Department of Medicine, University of Oxford, Oxford, UK

${ }^{2}$ Department of BioMedical Research, Immunology RIA, Inselspital, University of Bern, Bern, Switzerland
}

Received: 10 May 2019 Accepted: 10 May 2019

Published online: 23 May 2019

\section{Reference}

1. Mohsen, et al. Vaccination with nanoparticles combined with microadjuvants protects against cancer. J ImmunoTherapy Cancer. 2019;7:114. https://doi.org/10.1186/s40425-019-0587-z.

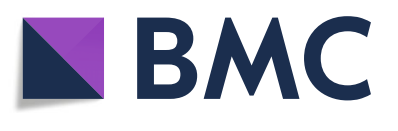

(c) The Author(s). 2019 Open Access This article is distributed under the terms of the Creative Commons Attribution 4.0 International License (http://creativecommons.org/licenses/by/4.0/), which permits unrestricted use, distribution, and reproduction in any medium, provided you give appropriate credit to the original author(s) and the source, provide a link to the Creative Commons license, and indicate if changes were made. The Creative Commons Public Domain Dedication waiver (http://creativecommons.org/publicdomain/zero/1.0/) applies to the data made available in this article, unless otherwise stated. 


\title{
Vaccination with nanoparticles combined with micro-adjuvants protects against cancer
}

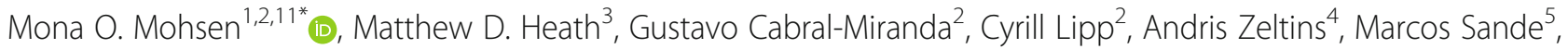
Jens V. Stein ${ }^{6}$, Carsten Riether ${ }^{7}$, Elisa Roesti ${ }^{2}$, Lisha Zha ${ }^{2,8}$, Paul Engeroff ${ }^{2}$, Aadil El-Turabi ${ }^{1}$, Thomas M. Kundig ${ }^{9}$, Monique Vogel ${ }^{2}$, Murray A. Skinner ${ }^{3}$, Daniel E. Speiser ${ }^{10}$, Alexander Knuth ${ }^{11}$, Matthias F. Kramer ${ }^{3}$ and Martin F. Bachmann ${ }^{1,2}$

\begin{abstract}
Background: Induction of strong T cell responses, in particular cytotoxic T cells, is a key for the generation of efficacious therapeutic cancer vaccines which yet, remains a major challenge for the vaccine developing world. Here we demonstrate that it is possible to harness the physiological properties of the lymphatic system to optimize the induction of a protective T cell response. Indeed, the lymphatic system sharply distinguishes between nanoscale and microscale particles. The former reaches the fenestrated lymphatic system via diffusion, while the latter either need to be transported by dendritic cells or form a local depot.
\end{abstract}

Methods: Our previously developed cucumber-mosaic virus-derived nanoparticles termed (CUMV TTVLPS) incorporating a universal Tetanus toxoid epitope $T$ T830-843 were assessed for their draining kinetics using stereomicroscopic imaging. A nano-vaccine has been generated by coupling p33 epitope as a model antigen to CUMV TTVLPs using bio-orthogonal Cu-free click chemistry. The CUMV TT-p33 nano-sized vaccine has been next formulated with the micron-sized microcrystalline tyrosine (MCT) adjuvant and the formed depot effect was studied using confocal microscopy and trafficking experiments. The immunogenicity of the nanoparticles combined with the micron-sized adjuvant was next assessed in an aggressive transplanted murine melanoma model. The obtained results were compared to other commonly used adjuvants such as B type CpGs and Alum.

Results: Our results showed that CUMV TT-VLPs can efficiently and rapidly drain into the lymphatic system due to their nano-size of $\sim 30 \mathrm{~nm}$. However, formulating the nanoparticles with the micron-sized MCT adjuvant of $\sim 5 \mu \mathrm{M}$ resulted in a local depot for the nanoparticles and a longer exposure time for the immune system. The preclinical nano-vaccine $\mathrm{CUMV}_{\text {TT}}$-P33 formulated with the micron-sized MCT adjuvant has enhanced the specific T cell response in the stringent B16F10p33 murine melanoma model. Furthermore, the micron-sized MCT adjuvant was as potent as B type CpGs and clearly superior to the commonly used Alum adjuvant when total CD8 ${ }^{+}$, specific p33 T cell response or tumour protection were assessed.

Conclusion: The combination of nano- and micro-particles may optimally harness the physiological properties of the lymphatic system. Since the nanoparticles are well defined virus-like particles and the micron-sized adjuvant MCT has been used for decades in allergen-specific desensitization, this approach may readily be translated to the clinic.

Keywords: Cucumber-mosaic virus CuMV, Virus-like particle VLP, Microcrystalline tyrosine MCT, Nano-vaccine

\footnotetext{
*Correspondence: Mona.mohsen@dbmr.unibe.ch; Monamona20@icloud.com

'Jenner Institute, Nuffield Department of Medicine, University of Oxford,

Oxford, UK

${ }^{2}$ Department of BioMedical Research, Immunology RIA, Inselspital, University

of Bern, Bern, Switzerland

Full list of author information is available at the end of the article
}

(c) The Author(s). 2019, corrected publication 2019. Open Access This article is distributed under the terms of the Creative Commons Attribution 4.0 International License (http://creativecommons.org/licenses/by/4.0/), which permits unrestricted use, distribution, and reproduction in any medium, provided you give appropriate credit to the original author(s) and the source, provide a link to the Creative Commons license, and indicate if changes were made. The Creative Commons Public Domain Dedication waiver (http://creativecommons.org/publicdomain/zero/1.0/) applies to the data made available in this article, unless otherwise stated. 


\section{Introduction}

Nanoparticles, specifically virus-like particles (VLPs), have succeeded as prophylactic vaccines and are now widely used. However, mounting an efficient immune response by therapeutic cancer vaccines is still a challenging area, highlighting the need for improved vaccine formulations. Three main parameters are pivotal for the development of an effective cancer vaccine: a cancer antigen, a delivery platform and an adjuvant. A large number of different formulations have been studied extensively in the past years; however head-to-head comparative data are still scarce and remain untested in humans [1]. Furthermore, vaccine formulations have not been studied or optimized with respect to the size of delivery platforms versus adjuvants.

Cucumber-mosaic virus (CuMV) coat protein may be expressed as a recombinant plant nano-sized virus-like particle (VLP) and has been studied as a promising candidate vaccine platform by displaying relevant epitopes for the induction of immune responses [2]. CuMV-VLPs are icosahedral nanoparticles capable of inducing both humoral and cellular immune responses by generating neutralizing antibodies (Abs), $\mathrm{CD}^{+} \mathrm{T}_{\mathrm{H}}$ cells and $\mathrm{CD} 8^{+}$cytotoxic $\mathrm{T}$ lymphocytes (CTLs) [3, 4]. Previously, we have developed an engineered nano-sized cucumber-mosaic virus-derived VLP by incorporating a universal Tetanus toxoid epitope TT830843 which we termed $\mathrm{CuMV}_{\text {TT }}$-VLPs [5]. The incorporation of the universal $\mathrm{T}$ cell epitope has been shown to be a powerful enhancer of the immune response in Tetanus toxoid immunized mice. Using the engineered nano-sized $\mathrm{CuMV}_{\mathrm{TT}}$-VLPs as a vaccine platform in humans is also expected to enhance their immune responses, since this epitope is recognized in essentially all humans who all have memory $\mathrm{CD}^{+} \mathrm{T}$ cells specific for the epitope due to vaccination against tetanus [5]. We have shown in several studies that $\mathrm{CuMV}_{\mathrm{TT}}-\mathrm{VLPs}$ nano-vaccine induce protective and therapeutic Ab responses in mice, horses and dogs [5-7].

Depot-forming adjuvants can prolong antigen presentation time to antigen-presenting cells (APCs), protect antigen from degradation and are optimal for $\mathrm{T}$ cell enhancement and clonal expansion [8,9]. Microcrystalline tyrosine (MCT) is a classical adjuvant used in the niche area of allergy immunotherapy, some of which include products that are licensed or are currently in late stage clinical development [10]. MCT forms crystals of natural L-Tyrosine and due to their micron-size, they cannot readily enter the lymphatics and remain at the injection site, forming a depot and local inflammation [11]. The introduction of MCT as a depot was based on its favorable biodegradable properties where a $48 \mathrm{~h}$ half-life at the injection site has been previously reported, making it suitable to adapt within formulations designed for weekly-dose administration as is also often used for cancer vaccines [11-14]. Moreover, early immunological studies in various animal models showed a more favorable
$\mathrm{T}_{\mathrm{H}}$ 1-biased immunological profile compared with the widely used Alum adjuvant [12, 15]. This is also further indicated where immunological synergy is observed when MCT is combined with Monophosphoryl Lipid $\mathrm{A}^{\circ}$, since it was shown that a combination of MCT and MPL was synergistic in enhancing murine antigen specific IgG $\mathrm{Ab}$ responses without increasing antigen specific IgE responses [15]. A short-course allergy vaccine using this adjuvant combination has recently completed a successful Phase II study in Europe and has been marketed as a named patient product for a number of years [16]. Further evidence has now emerged on MCT's more specific immunomodulatory functions. MCT activates the inflammasome in vitro and has been demonstrated to induce sustained and robust innate responses, including, specific adaptive $\mathrm{T}$ cell responses in a variety of immuneapplications [11, 13, 14]. Consequently, proof of concept studies using MCT across a broader vaccine scope is being pursued more rigorously and has since highlighted its adaptable nature within various formulation designs with other adjuvants / delivery systems in optimizing immune responses [17].

Here we harnessed the influence of particle's size on draining properties and their efficacy in producing effective CTLs response against an aggressive B16F10 tumour model by combining a $\mathrm{CuMV}_{\mathrm{TT}}$ nano-vaccine with the micronsize MCT adjuvant. We compared the response to other commonly used adjuvants such as the well-established Alum and the potent B type immunostimulatory CpGs. We show that the micron-sized MCT is a powerful adjuvant for $\mathrm{CuMV}_{\mathrm{TT}}$-p33 nano-vaccine displaying p33 epitope derived from LCMV, rivaling CpGs and clearly performing better than Alum in inducing CTLs and tumour protection. Thus, this combination may be an optimal way to formulate cancer nano-vaccines with micron-sized adjuvants thereby taking advantage of the physiological properties of the lymphatic system.

\section{Materials and methods \\ Expression and production of $\mathrm{CuMV}_{T T}$-VLPs}

$\mathrm{CuMV}_{\mathrm{TT}}$-VLPs expression and production was performed as described in detail in [5].

\section{Electron microscopy}

Physical stability and integrity of $\mathrm{CuMV}_{\mathrm{TT}^{-}}$-VLPs were visualized by transmission electron microscopy using the Philips CM12 EM. For imaging, sample-grids were glow discharged and $5 \mu \mathrm{l}$ of VLP solution was added for $30 \mathrm{~s}$. The grids were then washed $3 x$ with $\mathrm{ddH}_{2} \mathrm{O}$ and negativly stained with $5 \mu \mathrm{l}$ of $5 \%$ uranyl acetate for $30 \mathrm{~s}$. Finally, excess uranyl acetate was removed by pipetting and the grids were air dried for $10 \mathrm{~min}$. Images were taken with 84,000x and 110,000x magnification. 


\section{Mice}

Wild type C57BL/6 mice were purchased from Harlan. $R A G 2^{-/-}$mice on a C57BL/6 background were provided by Ochsenbein' lab and were bred in our pathogen-free animal facility. All in vivo experiments used 8-12-week-old female. All animal procedures were performed in accordance with the Swiss Animals Act (455.109.1) (September 2008, 5th) of University of Bern.

\section{Stereomicroscopic imaging}

WT C57BL/6 mice (8-12 weeks; Harlan) were anesthetized and prepared for imaging by shaving their right leg. Skin and adipose tissues were removed to expose the popliteal lymph node (LN) as described in detail in [18]. The anesthetized mice were then stabilized on a customized platform for imaging. The popliteal LN was located by bright field illumination imaging. A dose of $10 \mu \mathrm{g}$ of $\mathrm{CuMV}_{\mathrm{TT}}-$ VLPs vaccine was labelled with Alexa Fluor 488 (AF488) according to the manufacturer's instructions (Thermo Fisher SCIENTIFIC) and injected subcutaneously (s.c.) into the mouse footpad to study the draining kinetics of $\mathrm{CuMV}_{\mathrm{TT}^{-}}$-VLPs. Fluorescent light illumination with a CCD Nikon camera was used for imaging.

\section{Development of CuMV $\mathrm{TT}_{\mathrm{TT}}$-p33 nano-vaccine using bio- orthogonal cu-free click chemistry}

$\mathrm{CuMV}_{\mathrm{TT}^{-}}$-VLPs were derivatized using 10-fold molar excess of DBCO cross-linker (Dibenzocyclooctyne- $N$-hydroxysuccinimidyl ester) (Sigma-Aldrich) in $2 \mathrm{mM}$ EDTA and $20 \mathrm{mM} \mathrm{NaP}$, pH 7.5 for $30 \mathrm{~min}$ at RT in a shaker at $400 \mathrm{rpm}$. Excess uncoupled DBCO was removed by diafiltration steps. Modified p33 peptide H-KAVYNFATMGGCK(N3)-NH2 was purchased from (Pepscan PRESTO) and reconstituted using DMSO. 10 -fold molar excess of the modified peptide was then added to the derivatized $\mathrm{CuMV}_{\mathrm{TT}}$-VLPs. 5-fold molar excess of TCEP was added to liberate cysteine residues at the C-terminus on the VLPs. The coupling was performed for $1 \mathrm{~h}$ at RT in a shaker at $400 \mathrm{rpm}$. Excess peptide was removed using $100 \mathrm{kDa}$ MWCO amicon centrifuge tubes (Sigma Aldrich). The efficiency of the coupling was tested by SDS-PAGE (Bio-RAD) and assessed by densitometric analysis of SDS-PAGE of $\mathrm{Cu}$ $\mathrm{MV}_{\mathrm{TT}}$-VLP monomer bands compared to $\mathrm{CuMV}_{\mathrm{TT}}-\mathrm{VLP}$ monomer plus p33 after coupling.

\section{Depot effect with confocal microscopy}

$10 \mu \mathrm{g}$ of $\mathrm{AF} 488 \mathrm{CuMV}_{\mathrm{TT}}$-p33 nano-vaccine formulated or not formulated with $50 \mu \mathrm{l}$ of $4 \% \mathrm{MCT}$ adjuvant was injected in WT C57BL/6 mice footpads (8-12 weeks; Harlan) using isoflurane anesthesia. Popliteal LNs were collected $3 \mathrm{~h}, 24 \mathrm{~h}, 48 \mathrm{~h}, 96 \mathrm{~h}$ and $216 \mathrm{~h}$ after injection. Lymph nodes were fixed in PFA $2 \%$ for $3 \mathrm{~h}$ at RT. The LNs were transferred to CUBIC 1 medium [19] for 8 days at $37^{\circ} \mathrm{C}$ and scanned at Leica SP8 with 10x lense, $1024 \times 1024$ resolution, tile scan was performed in LNs that were not fitting in the field of view of the 10x lense. Images were analyzed and segmented the individual CMV particles using Imaris Software v9.2.1 (Bitplane).

\section{Depot effect with trafficking experiment}

$10 \mu \mathrm{g}$ of AF488 $\mathrm{CuMV}_{\mathrm{TT}}$-p33 nano-vaccine formulated or not formulated with $50 \mu \mathrm{l}$ of $4 \%$ MCT adjuvant was injected in WT C57BL/6 mice footpads (8-12 weeks; Harlan) using isoflurane anesthesia. Popliteal LNs were collected $3 \mathrm{~h}, 24 \mathrm{~h}, 48 \mathrm{~h}, 96 \mathrm{~h}$ and $216 \mathrm{~h}$ after injection and treated with collagenase D (Roch) in 10\%FSC containing DMEM for $25 \mathrm{~min}$ at $37^{\circ} \mathrm{C}$. Cells were stained with live/ dead dye (eBioscience) and analyzed for total number of

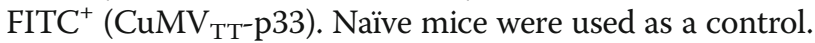

Measuring p33 specific $\mathrm{CD}^{+} \mathrm{T}$ cell response in the spleen Six groups of WT C57BL/6 mice (8-12 weeks old; Harlan) were vaccinated s.c. with a single dose of: 1st group $70 \mu \mathrm{g}$ of $\mathrm{CuMV}_{\mathrm{TT}}$-VLPs, 2nd group $70 \mu \mathrm{g}$ of $\mathrm{CuMV}_{\mathrm{TT}}$-Actin nano-vaccine, $3 \mathrm{rd}$ group $70 \mu \mathrm{g}$ of $\mathrm{CuMV}_{\mathrm{TT}-\mathrm{p} 33}$ nano-vaccine, 4th group $70 \mu \mathrm{g}$ of $\mathrm{CuMV}_{\mathrm{TT}} \mathrm{p} 33$ nano-vaccine admixed with $15 \mathrm{nmol}$ of B type CpGs 5' '-TCC ATG ACG TTC CTG ATG CT-3' ') (20 mer) (Invivogen), 5th group

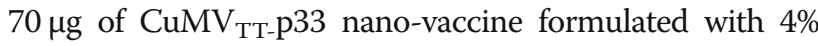
MCT adjuvant $(40 \mathrm{mg} / \mathrm{ml}$ ) (Allergy Therapeutics Ltd. Worthing, UK) and the 6th group $70 \mu \mathrm{g}$ of CuMV $\mathrm{Cu}_{\text {TT-p33 }}$ nano-vaccine formulated with $100 \mu \mathrm{l}$ of Alhydrogel adjuvant $2 \%$ (InvivoGen). Formulating $\mathrm{CuMV}_{\mathrm{TT}}$-p33 with MCT or Alum requires prolonged mixing of both components for $1 \mathrm{~h}$ at RT in shaker at $400 \mathrm{rpm}$ to ensure adequate adsorption of the VLPs on MCT or Alum surface. Seven days later, spleens were collected and staining was performed using Fc-block, live/dead, anti-CD8 (eBioscience) and p33 (KAVYNFATM) tetramer designed using $\mathrm{H}-2 \mathrm{Db}$ allele and PE fluorochrome (TCMetrix).

\section{Intra-cellular cytokine (ICS) staining for IFN- $\gamma$ and TNF-a} Intra-cellular cytokine staining was performed on spleens and TILs of vaccinated WT C57BL/6 mice for measuring of IFN- $\gamma$ and TNF- $\alpha$ cytokines as described in detail in [20].

\section{Tumour experiments}

$1 \times 10^{6}$ cells of B16F10p33 melanoma cell line (From Ochsenbein lab) was injected into the flank of $R A G 2^{-/-}$ C57BL/6 mice (From Ochsenbein lab). Twelve days later the growing tumours were collected and processed into $\sim 2 \mathrm{~mm}^{2}$ fragments for transplantation into the flank of WT C57BL/6 mice (8-12 weeks old; Harlan) under full anesthesia. The transplanted WT C57BL/6 mice were treated 3 times over 14 days (mice in the control group reached the humane end-point at day 14). In the first 
tumor experiment mice were vaccinated s.c. as follows: 1st group $70 \mu \mathrm{g}$ of $\mathrm{CuMV}_{\mathrm{TT}}$-VLPs, 2nd group $70 \mu \mathrm{g}$ of $\mathrm{CuMV}_{\mathrm{TT}}$-p33 nano-vaccine and 3rd group $70 \mu \mathrm{g}$ of $\mathrm{CuMV}_{\mathrm{TT}}$-p33 nano-vaccine formulated with $4 \% \mathrm{MCT}$ adjuvant $(40 \mathrm{mg} / \mathrm{ml}$ ) (Allergy Therapeutics Ltd. Worthing, UK). In the second tumour experiment mice were vaccinated s.c. as follows: 1st group $70 \mu \mathrm{g}$ of $\mathrm{CuM}$ $\mathrm{V}_{\mathrm{TT}}$-VLPs, 2nd group $70 \mu \mathrm{g}$ of $\mathrm{CuMV}_{\mathrm{TT}}$-p33 nano-vaccine admixed with $15 \mathrm{nmol}$ of B type CpGs 5"'-TCC ATG ACG TTC CTG ATG CT-3'') (20 mer) (Invivogen), 3rd group $70 \mu \mathrm{g}$ of $\mathrm{CuMV}_{\mathrm{TT}^{-}} \mathrm{p} 33$ nano-vaccine formulated with $4 \% \mathrm{MCT}$ adjuvant $(40 \mathrm{mg} / \mathrm{ml}$ ) (Allergy Therapeutics Ltd. Worthing, UK) and 4th group $70 \mu \mathrm{g}$ of $\mathrm{CuMV}_{\mathrm{TT}}$-p33 nano-vaccine formulated with $100 \mu \mathrm{l}$ of Alhydrogel adjuvant 2\% (InvivoGen). Tumour growth was followed daily and measured using calipers. Tumours were collected and measured on day 14. TILs were isolated by treating the tumours with collagenase D (Roch) in $10 \%$ FSC containing DMEM for $25 \mathrm{~min}$ at $37^{\circ}$ C. Cells were passed through a cell strainer of $100 \mu \mathrm{m}$ (Corning) and TILs were separated using Ficoll (Sigma-Aldrich). TILs were stained with Fc block, live/dead, anti-CD8 (eBioscience) and p33 tetramers (TCMetrix).

\section{Statistics}

Tumour growth curves were compared by calculating the area-under curve (AUC) and analyzed by One-Way ANOVA (Turkey's Multiple Comparison Test). Other data has been analyzed and presented using Unpaired Student's $t$ test. GraphPad Prism7 or 8 software was used for the analysis.

\section{Results}

CUMV $_{T T}$-VLPs demonstrate fast kinetics and constitute an efficient vaccine platform for displaying target peptides/ epitopes

In a first step, we produced the engineered $\mathrm{CuMV}_{\mathrm{TT}}-\mathrm{VLPs}$ and confirmed their morphology, integrity and nano-size by electron microscopy (Fig. 1a). Next, we studied the draining-kinetics of $\mathrm{CuMV}_{\mathrm{TT}}$-VLPs utilizing stereomiscroscopic imaging. To this end, $\mathrm{CuMV}_{\mathrm{TT}}$-VLPs were labelled with the fluorescent dye AF488 and injected s.c. in the footpad of WT C57BL/6 mice. Our results show that the labelled nanoparticles accumulate in the popliteal LN in less than $1 \mathrm{~min}$, demonstrating fast and efficient draining

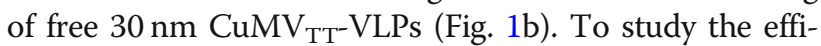
cacy of CuMV $\mathrm{TT}_{\mathrm{T}}$-VLPs as a cytotoxic $\mathrm{T}$ cell based nanovaccine, we have used the $H-2 D^{b}$ restricted $\mathrm{p} 33$ peptide derived from LCMV as a model antigen. The model peptide was coupled to $\mathrm{CuMV}_{\mathrm{TT}}$-VLPs using our developed method based on "biorthogonal $\mathrm{Cu}$-free click chemistry" as illustrated in Fig. 1c. The efficiency of the coupling was tested using SDS-PAGE. The additional bands above the
VLP monomer show efficient coupling of p33 peptide to $\mathrm{CuMV}_{\mathrm{TT}}$-VLP monomers (Fig. 1d).

\section{The micron-sized MCT adjuvant displays depot effect when combined with $\mathrm{CuMV}_{\mathrm{TT}}$-p33 nano-vaccine}

Microcrystalline tyrosine (MCT) is considered to be a depot-forming adjuvant facilitating the slow but prolonged release of antigens. Formulating the nano-vaccine $\mathrm{CuMV}_{\mathrm{TT}}$-p33 with the micron-sized MCT adjuvant may therefore enhance the slow release of the nanoparticles displaying the target epitope and extend their exposure to the immune system. To test that, we have first formulated the AF488 $\mathrm{CuMV}_{\mathrm{TT}}$-p33 nano-vaccine with MCT in vitro to visualize the binding of the nanoparticles to the micron-sized MCT adjuvant by confocal microscopy. The results showed that the labelled nanoparticles bind and decorate the surface of the micron-sized crystals (Fig. 2a and S1). To further study this hypothesis in vivo, we injected the AF488 $\mathrm{CuMV}_{\mathrm{TT}}$-p33 nano-vaccine (alone or formulated with MCT adjuvant) into the footpad of WT C57BL/6 mice as illustrated in Fig. $2 \mathrm{~b}$ and collected the popliteal LNs at different time-points $3 \mathrm{~h}, 24 \mathrm{~h}, 48 \mathrm{~h}, 96 \mathrm{~h}$ and $216 \mathrm{~h}$ to assess the persistence of the labelled nanoparticles by flow cytometry. The results demonstrate that $\mathrm{CuMV}_{\mathrm{TT}}-\mathrm{p} 33$ injected in free form disappears from the popliteal LN in 4 days while formulating the nano-vaccine with the micron-sized MCT adjuvant causes slower but prolonged release of the nanoparticles over 9 days (Fig. 2c). These findings were also supported when imaging the popliteal LNs by confocal microscopy (Fig. 2d and S2-S5).

Formulating $\mathrm{CuMV}_{\mathrm{TT}}$-p33 nano-vaccine with the micronsized MCT adjuvant induces significant p33 specific T cell response and enhances cytokines secretion

We then tested whether formulating $\mathrm{CuMV}_{\mathrm{TT}}-\mathrm{p} 33$ nano-vaccine with MCT would enhance the specific $\mathrm{T}$ cell response in vivo. Therefore, six vaccines and formulations were prepared as outlined in Fig. 3a. CpG 1668 and Alum were independently formulated with $\mathrm{CuMV}_{\mathrm{TT}}$-p33 nano-vaccine to benchmark the potency of the micron-sized MCT adjuvant. Actin coupled to $\mathrm{CuMV}_{\mathrm{TT}}$-VLPs was used as a non-specific control peptide to show that the obtained response is specific to p33 peptide. The different vaccine formulations were injected once s.c. in WT C57BL/6 mice and spleens were collected seven days later for tetramer and intra-cellular cytokine staining. The H2-D ${ }^{\mathrm{b}}$ allele p33 (KAVYNFATM) tetramers have been used to enable direct visualization and quantification of p33 specific $\mathrm{T}$ cells. The results showed that admixing $\mathrm{CuMV}_{\mathrm{TT}}$-p33 nano-vaccine with CpGs 1668 or formulating it with the micron-sized MCT adjuvant induced the highest percentage of p33 specific $\mathrm{T}$ cells upon single injection (Fig. $3 \mathrm{~b}$ and $\mathrm{f}$ ). We then assessed the cytokine secretion in each group, 


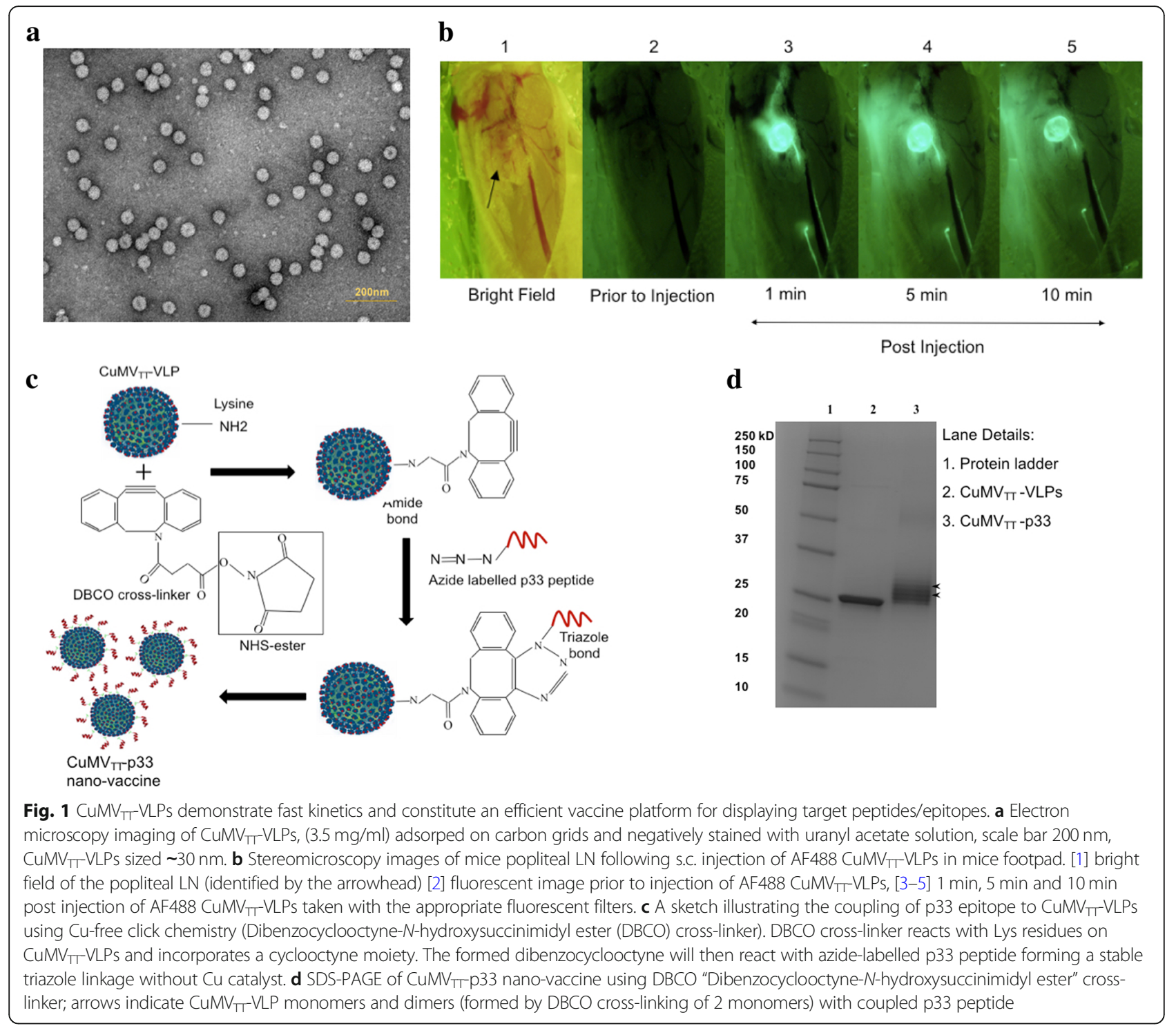

mainly IFN- $\gamma$ and TNF- $\alpha$. The secretion of both cytokines was enhanced when combining the nano-vaccine with CpGs 1668 or MCT adjuvant (Fig. 3c and d). Formulating $\mathrm{CuMV}_{\mathrm{TT}}$-p33 nano-vaccine with Alum did not enhance the production of $\mathrm{p} 33$ specific $\mathrm{T}$ cells nor the secretion of IFN- $\gamma$ or TNF- $\alpha$. Furthermore, when analyzing the dual secretion of IFN- $\gamma$ and TNF- $\alpha$ in polyfunctional T cells, a large percentage of the cytokine-producing $\mathrm{T}$ cells was found to be polyfunctional in the groups admixed with CpGs 1668 or MCT (Fig. 3e and g).

Formulating CuMV $\mathrm{TT}_{\mathrm{TT}} \mathrm{p} 33$ nano-vaccine with the micronsized MCT adjuvant delays tumour growth and enhances $\mathrm{CD}^{+}$and $\mathrm{p} 33$ specific CTL infiltration into B16F10p33 tumours

In order to test the immunogenicity and efficacy of combining nanoparticles with micron-sized adjuvants in a melanoma model, we have adapted a challenging melanoma murine model based on transplanting $\sim 2 \mathrm{~mm}^{3}$ of B16F10p33 tumour fragment into the flank of WT C57BL/6 mice. The tumour was allowed to grow for 5 days more following transplantation before the vaccination regimen started (Fig. 4a). Three groups were prepared as illustrated in Fig. $4 \mathrm{~b}, \mathrm{CuMV}_{\mathrm{TT}^{-}}$-VLPs as a control, $\mathrm{CuMV}_{\mathrm{TT}^{-}}$-p33 nano-vaccine alone and $\mathrm{CuM}$ $\mathrm{V}_{\mathrm{TT}}$-p33 nano-vaccine formulated with MCT. Tumours were collected for analysis 14 days after tumour transplantation as the control group reached the ethically allowed maximal size of $\sim 1000 \mathrm{~mm}^{3}$. The obtained results revealed that formulating $\mathrm{CuMV}_{\text {TT-}}$-p33 nanovaccine with the micron-sized MCT could significantly hinder B16F10p33 tumour progression when compared to the control group $(p<0.0001)$ or to the group vaccinated with $\mathrm{CuMV}_{\mathrm{TT}}$-p33 nano-vaccine alone $(p$ 0.0055) 


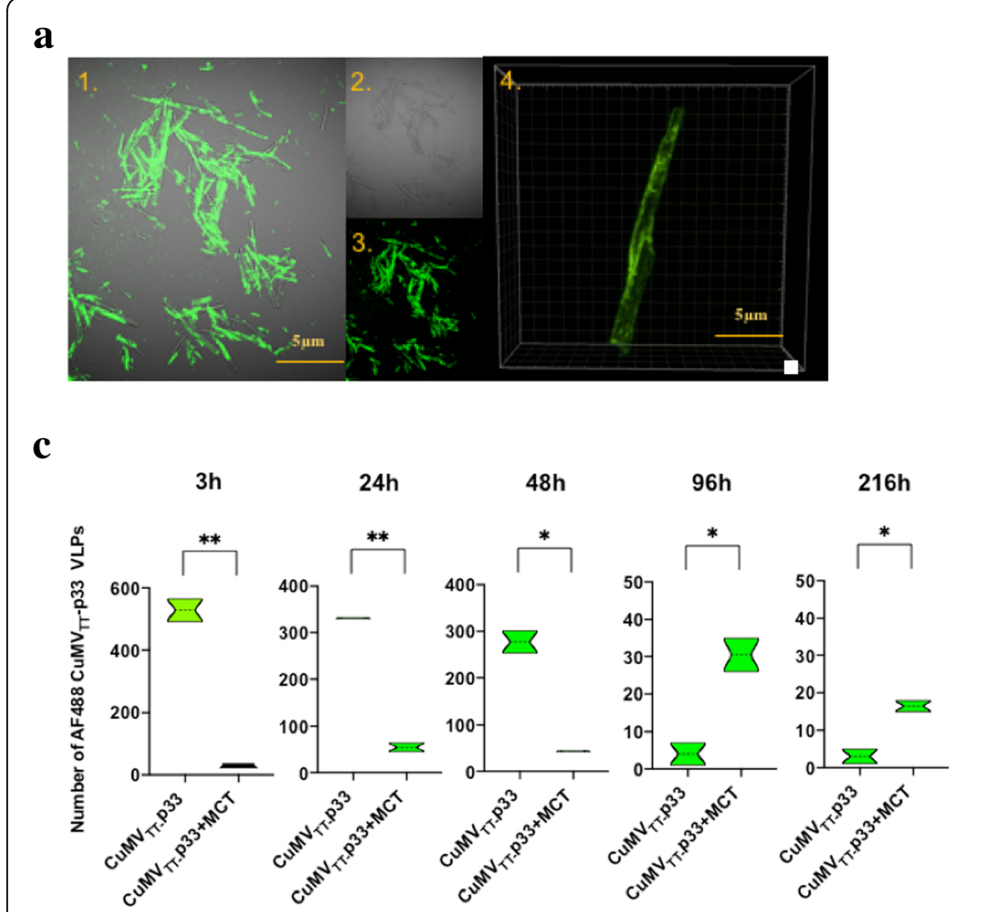

b

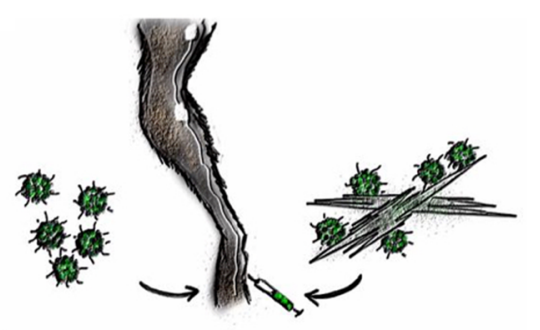

d

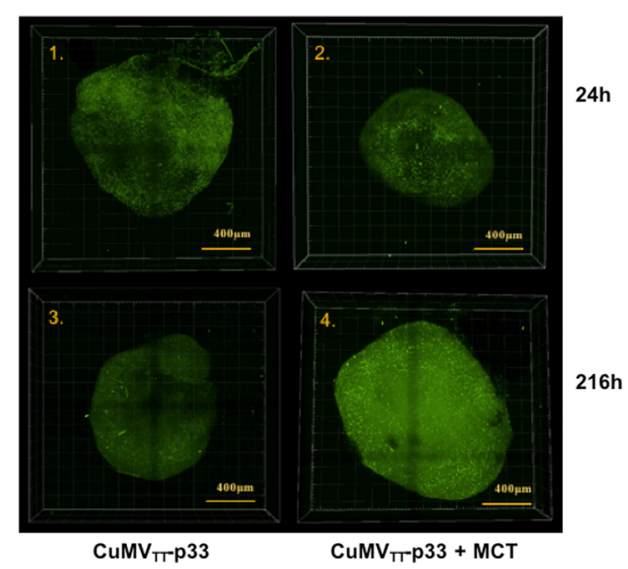

Fig. 2 The micron-sized MCT adjuvant displays depot effect when combined with CuMV ${ }_{T-p 33}$ nano-vaccine. a Confocal microscopy imaging of AF488 CuMV T-p33 nano-vaccine following formulation with the micron-sized MCT adjuvant, 1) GFP signal of AF488 CuMV T-p33 nano-vaccine 2) bright light field 3) an overlay 4-6 3D images with bright light field 4) an MCT crystal decorated with CUMV TT-p33 nano-vaccine particles. b A sketch illustrates the two prepared nano-vaccines, the 1st group consists of AF488 CuMV TT-p33 nano-vaccine and the 2nd consists of AF488 $\mathrm{CuMV}_{\pi T}$-p33 nano-vaccine formulated with MCT adjuvant. $\mathbf{d}$ Total number of AF488 CuMV ${ }_{T-p}$-p3 nanoparticles in the popliteal LNs collected $3 \mathrm{~h}$, $24 \mathrm{~h}, 48 \mathrm{~h}, 96 \mathrm{~h}$ and $216 \mathrm{~h}$ post-injection of the two prepared nano-vaccine groups in mice footpad. Statistical analysis by unpaired Student's $t$ test. c Confocal microscopy images of popliteal LNs $24 \mathrm{~h}$ and $216 \mathrm{~h}$ post-injection of the two prepared nano-vaccine groups in mice footpad, GFP signal was detected in LNs, whole mount view of z-stacks was acquired. One representative experiment of 3 similar experiments is shown

(Fig. 4c and d). Tumour-infiltrating lymphocytes (TILs) represent a prognostic factor for effective immune responses especially in melanoma [21, 22]. Therefore, we measured the total number of the infiltrated $\mathrm{CD} 8^{+} \mathrm{T}$ cells and $\mathrm{p} 33$ specific CTLs (Fig. 4e) in TILs and calculated the density of these cells in each vaccinated group (number of cells divided by tumour volume). Formulating $\mathrm{CuMV}_{\mathrm{TT}}$-p33 nano-vaccine with MCT significantly increased the density of total $\mathrm{CD} 8^{+}$ T cells ( $p .0 .0024)$ (Fig. 4f) as well as the density of p33 specific CTL measured by tetramers (p. 0.0093) (Fig. 4g) in comparison to mice vaccinated with $\mathrm{CuMV}_{\mathrm{TT}}$-p33 nanovaccine alone. IFN- $\gamma$ production was also enhanced when formulating $\mathrm{CuMV}_{\mathrm{TT}} \mathrm{-p} 33$ with MCT (Fig. 4h). Thus, formulating the a nano-vaccine in MCT enhanced infiltration by specific $\mathrm{T}$ cells as well as anti-tumor protection.

\section{The micron-sized MCT adjuvant shows comparable} activity to B-type CpGs and is superior to alum in driving protection against B16F10p33 melanoma

The immunogenicity of the $\mathrm{CuMV}_{\text {TT-p33 nano-vaccine }}$ formulated with the micron-sized MCT adjuvant was then compared to the immune-stimulatory B type CpGs and the widely used adjuvant Alum using the same aggressive B16F10p33 tumour model. Four groups were prepared as shown in Fig. 5a. The results again revealed that formulating $\mathrm{CuMV}_{\mathrm{TT}}-\mathrm{p} 33$ nano-vaccine with $\mathrm{CpGs}$ 1668 or MCT would significantly $(p 0.0072,0.0129$ respectively) hinder B16F10p33 tumour progression, which was not the case when formulating $\mathrm{CuMV}_{\mathrm{TT}}-\mathrm{p} 33$ with Alum ( $p$ 0.4188) (Fig. 5b). In a next step, we measured the total number of infiltrated $\mathrm{CD}^{+} \mathrm{T}$ cells (Fig. 5c) and p33 specific CTLs (Fig. 5d) in the tumour and calculated the density. There was a general increase in the groups mixed with CpGs 1668 or formulated with MCT or Alum (Fig. 5e and f). Formulating $\mathrm{CuMV}_{\mathrm{TT}}$-p33 nano-vaccine with the micron-sized MCT adjuvant showed comparable results to CpGs 1668, the gold standard adjuvant in mice. Furthermore, MCT adjuvant was more potent at increasing the infiltration of total $\mathrm{CD}^{+}$and $\mathrm{p} 33$-specific $\mathrm{T}$ cells into the tumour microenvironment when compared to formulating the vaccine with Alum. 


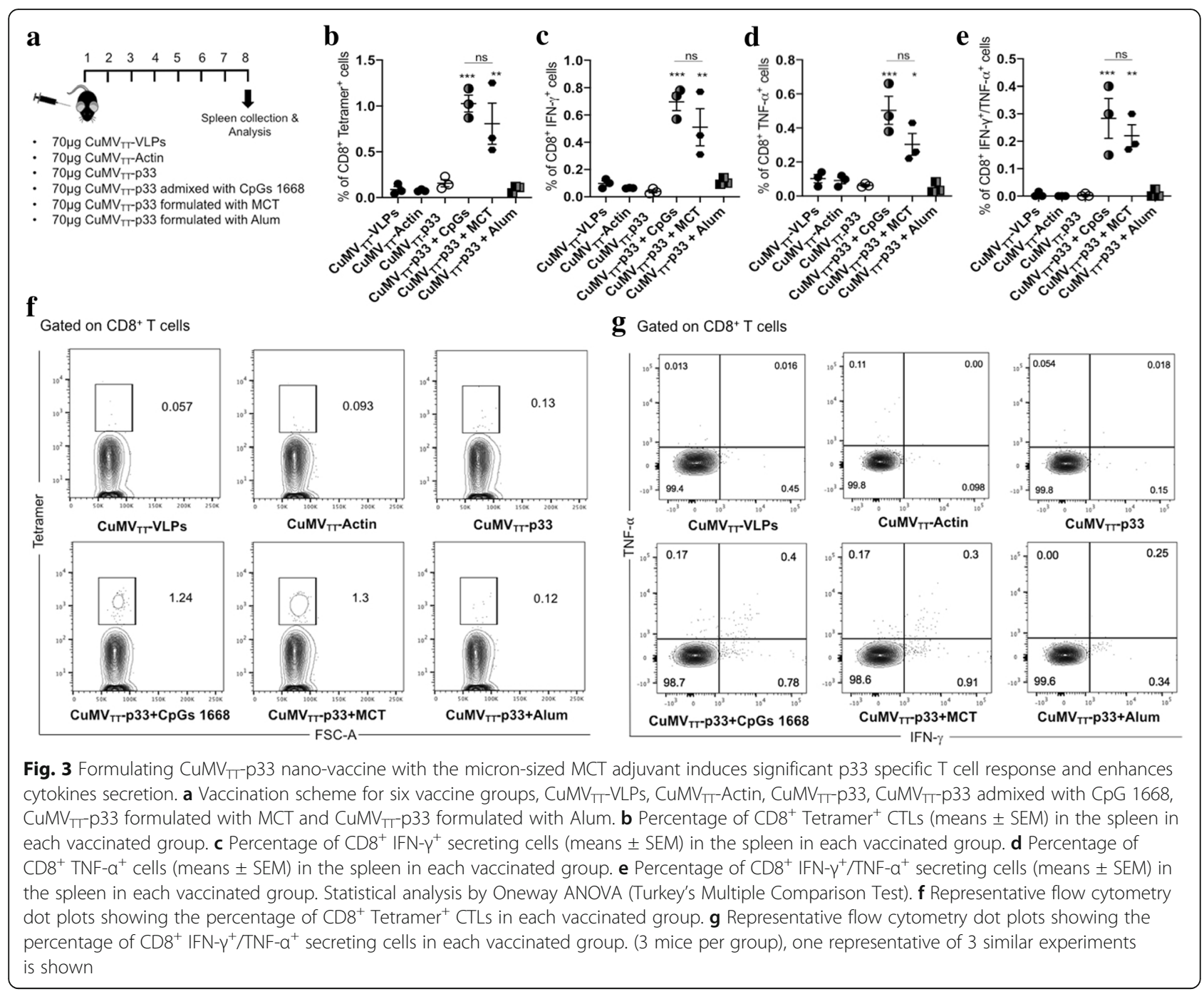

The micron-sized MCT adjuvant shows comparable production of cytokines to $\mathrm{B}$ type $\mathrm{CpGs}$ and is superior to alum in B16F10p33 melanoma

Production of IFN- $\gamma$ and TNF- $a$ cytokines by TILs was also assessed upon immunization with $\mathrm{CuMV}_{\text {TT}}-\mathrm{p} 33$ admixed with B type CpGs or formulated with MCT or Alum. Production of IFN- $\gamma$ (Fig. 6a and b) and TNF- $a$ (Fig. 6c and d) was assessed separately or as dual cytokine production in polyfunational T cells (Fig. 6e and f). There was no significant difference in the production of single IFN- $\gamma$, TNF- $a$ or dual IFN- $\gamma /$ TNF cytokines between the groups admixed with CpGs 1668 or formulated with MCT adjuvant ( $p$ 0.3986, 0.3433 and 0.4120 respectively). However, there was a significant difference when comparing the group formulated with MCT to the one formulated with Alum ( $p 0.0179,0.0187$ and 0.006, respectively).

\section{Discussion}

In this study, we have developed cucumber mosaic virus-derived nanoparticles genetically fused to the universal $\mathrm{T}$ cell epitope of Tetanus toxin (CuM $\mathrm{V}_{\mathrm{TT}}$-VLPs). These nanoparticles constitute a promising vaccine platform as the incorporated Tetanus toxin epitope can enhance their immunogenicity and the production of robust $\mathrm{Ab}$ and CTL responses especially in aging populations [5, 6]. Displaying epitopes on $\mathrm{CuMV}_{\mathrm{TT}}$-VLP's exterior surface can be achieved by simple chemical techniques such as the SMPH heterobifunctional cross-linker. Such techniques have shown efficacy and good results in many different clinical settings [23-25]. However, we have lately enhanced the coupling efficacy of epitopes to bacteriophage $\mathrm{Q} \beta$-VLP using the biorthogonal $\mathrm{Cu}$-free click chemistry (Mohsen et al., submitted). Here we have shown that such method can also be efficiently used to couple peptides/epitopes to $\mathrm{CuMV}_{\mathrm{TT}}$-VLPs. Generally, $\mathrm{Cu}$-free click chemistry is a safe, non-toxic coupling method as the azide moiety attached to the target epitope does not react with any of the body's natural molecules [26-28]. 


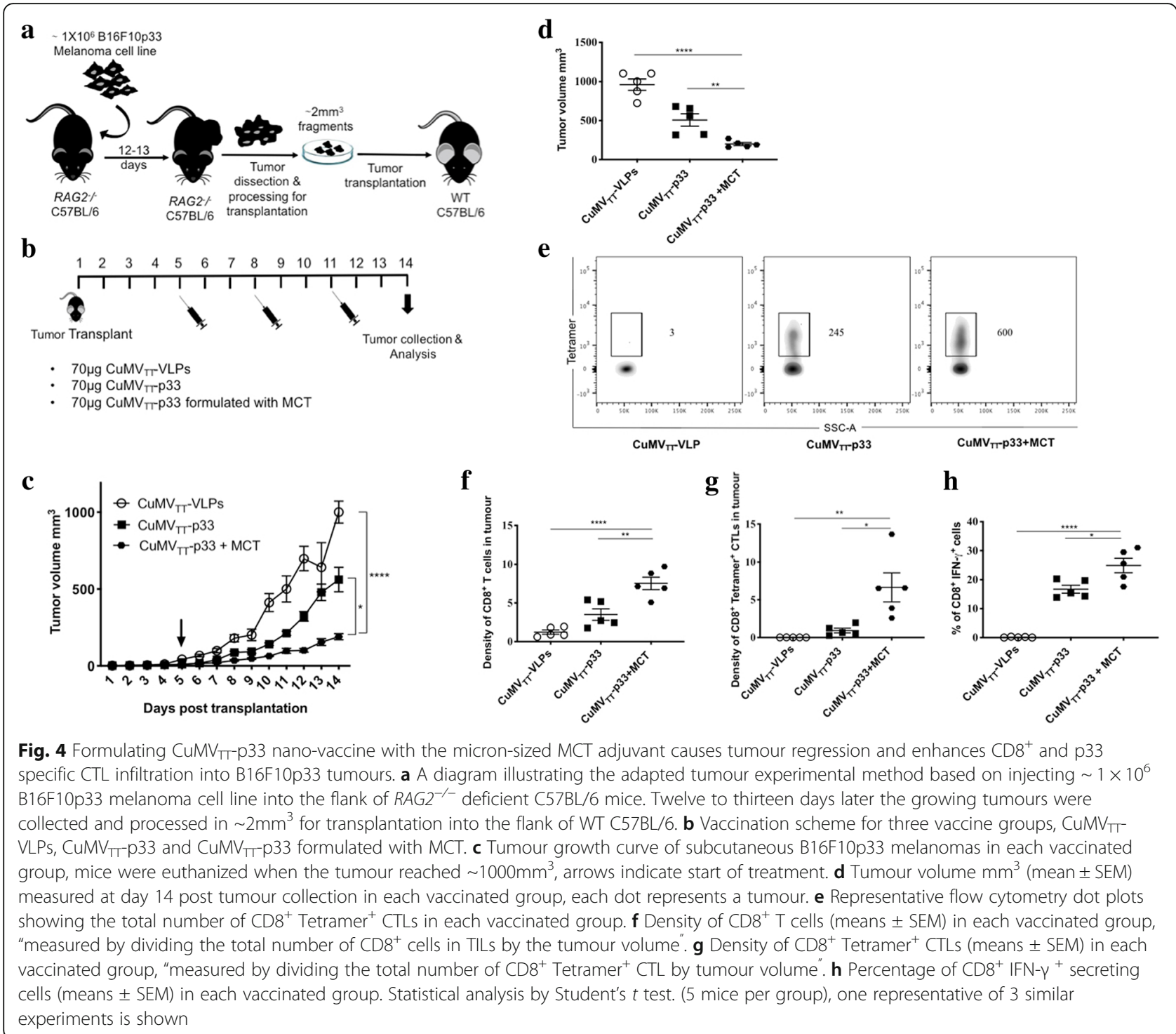

Immunostimulatory adjuvants such as synthetic CpG-oligonucleotides are TLR-agonists and have shown promising therapeutic potential by activating both the innate and adaptive immune system [29-31]. CpGs have also been successfully used clinically to adjuvant cancer vaccines [32, 33]. However, CpGs have some drawbacks including their unfavourable pharmacokinetics and their propensity to cause splenomegaly, at least in mice [34, 35]. It has been shown previously that packaging CpGs into VLPs such as $\mathrm{Q} \beta$ or $\mathrm{HBcAg}$ can improve the pharmacokinetics and dynamics of the DNA oligomers [36]. Nevertheless, it is not always feasible to package VLPs with CpGs as some nanoparticles are unstable and packaging with reassembly processes may be time consuming when targeting translational approaches. Furthermore, TLR-9 agonists have been widely used with VLP-based vaccines to enhance $\mathrm{T}$ and $\mathrm{B}$ cell responses mostly in mice and more rarely in humans [37]. In mice, TLR-9 is expressed by all DCs while in human it is mainly expressed by pDCs in lymphoid organs but not by conventional DCs [38]. pDCs, however, respond much more efficiently to A type CpGs rather than B type $\mathrm{CpGs}$ as only the former induce strong production of type I IFN [39]. Hence, it may be difficult to directly translate findings with $\mathrm{B}$ type $\mathrm{CpGs}$ from mice to humans. With this respect, it is interesting to note that $\mathrm{CuMV}_{\mathrm{TT}}$ VLPs naturally package RNA from the E. coli expression strain, a ligand for TLR7/8 which is expressed in all human DCs.

Several preclinical and clinical studies have indicated that some of the adjuvants used in licensed products are not optimal for developing effective cancer vaccines. Examples are the commonly used Montanide (Incomplete Freund's adjuvant) and Alum [40-43]. Such limitations 


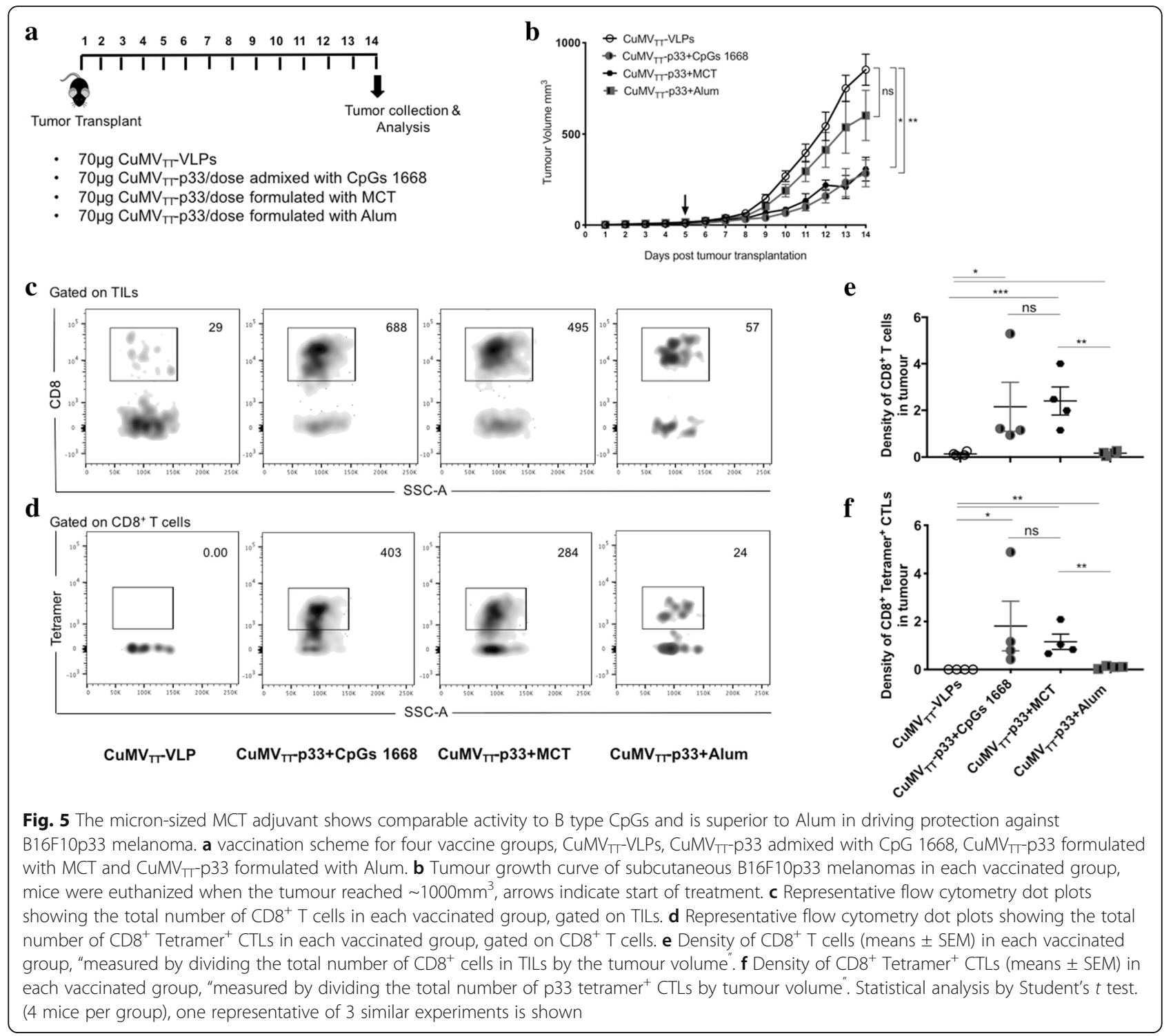

may include the inadequate ability of these adjuvants to induce CTLs [44]. Nevertheless, use of B-type CpGs and Alum in mice is useful where direct comparative adjuvant studies are concerned. Since they are well characterized in mice, both adjuvants are a good benchmark when comparing other new or newly used adjuvants such as MCT.

MCT is a micron-sized adjuvant that forms crystals of about $\sim 5 \mu \mathrm{M}$ that readily adsorb proteins including protein-based nanoparticles such as VLPs. MCT is well known in the world of specific allergy immunotherapy, as it is categorized as a depot excipient in registered subcutaneous immunotherapy products for the treatment of allergies. However, the knowledge about its mechanism of action and its potential in different fields of vaccinology is only expanding now. In a recent study, MCT was shown to be an effective adjuvant in allergen-specific immunotherapy. Protection against IgE-mediated allergic response was achieved in mouse models, independently of inflammasome and TLR signaling in vivo. As has been seen for Alum, the adjuvant activity of MCT was independent of the inflammasome in vivo despite its ability to activate the inflammasome in vitro [11]. In malaria, MCT has been shown to consistently enhance protective IgG responses and more protective IgG subclasses resulting in enhanced protection against malaria. Similar observations were made for influenza vaccine candidates $[13,14,17]$.

Here, we have studied the draining kinetics of $\mathrm{CuMV}_{\mathrm{TT}}$-p33 vaccine alone or formulated with adjuvant MCT. Our results indicate that the free AF488 $\mathrm{CuMV}_{\mathrm{TT}^{-}}$- 33 can drain rapidly into the draining LN but fades away after $\sim 4$ days. In contrast, the release of

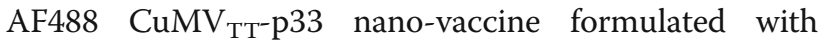




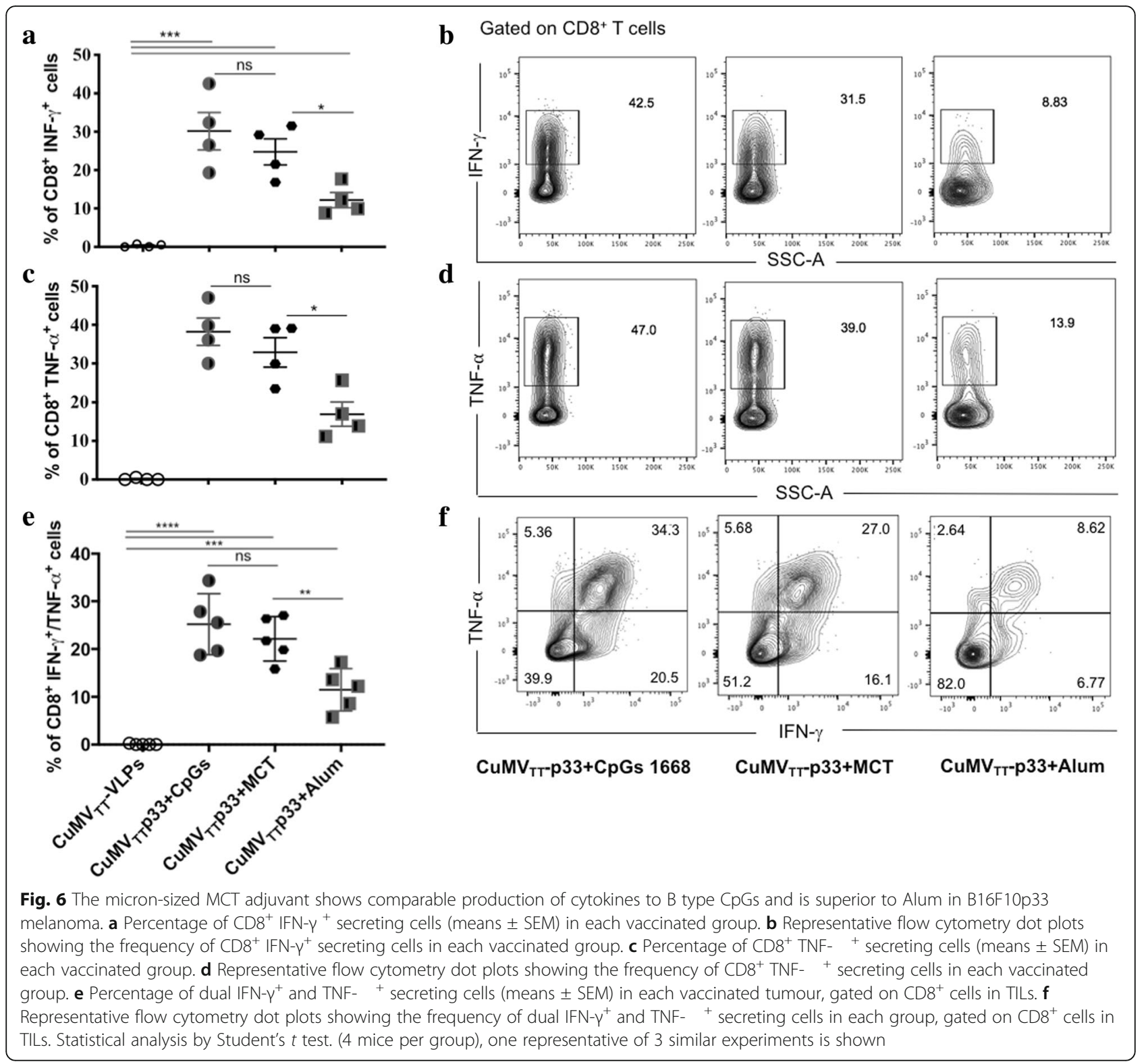

MCT was delayed and more consistent over a longer period of time. Previous studies have mostly supported the importance of the depot-forming adjuvants in $\mathrm{T}$ cell based vaccine development as they delay the clearance of the vaccine that results in enhancing the generation of effective antigen-specific CTL responses $[45,46]$.

To study the immunogenicity of the developed $\mathrm{CuMV}_{\mathrm{TT}}$-p33 nano-vaccine formulated with MCT, the protective capacity of the induced CTL-responses was assessed in an aggressive murine melanoma model consisting of B16F10 cells transfected with $\mathrm{H}-2 \mathrm{D}^{\mathrm{b}}$ restricted p33 epitope derived from LCMV. To generate tumors with maximal physiological properties, we have used a challenging tumour model based on transplanting solid tumour fragments rather than single cell suspension.
The transplantation of solid tumor fragments allows studying tumor development in the context of already established tumor stroma which is more reflective of the physiological situation. When transplanted as solid fragments, even very immunogenic tumors grow in immunocompetent hosts and the vascularized tumours rapidly grow to lethal size $(47-50)$. The results show that formulating $\mathrm{CuMV}_{\mathrm{TT}}$-p33 nano-vaccine with $\mathrm{MCT}$ was more potent in blocking tumour growth than using the nano-vaccine alone. The protective capacity of the $\mathrm{CuMV}_{\mathrm{TT}^{-}}$-p33 with MCT is therefore strong, as the model used is very challenging. Previous studies have indicated that melanoma tumours exhibiting increased numbers of tumour infiltrating $\mathrm{CD}^{+} \mathrm{T}$ cells have better prognosis. TILs have led to a better understating of the 
interaction between hosts and tumours, mainly because their study allowed better characterization of effective therapeutic responses [22, 47]. TILs isolated from the vaccinated groups have been assessed for the presence of p33 specific CTLs by means of tetramers and intracellular cytokine staining. $\mathrm{CuMV}_{\text {TT-}}$-p33 vaccine formulated with MCT adjuvant enhanced the infiltration of $\mathrm{CD}^{+}$ and p33 specific CTLs into the tumour and the production of IFN- $\gamma$. These results indicate that MCT may be a promising cancer adjuvant. When comparing MCT adjuvant to the potent B type CpGs or the widely used Alum, the overall adjuvants activity of MCT was comparable to CpGs and superior to Alum.

It has been previously seen that Alum may increase overall IgG responses at least as good as MCT. In contrast to Alum, however, MCT induced superior IgG2a responses, which is usually associated with $\mathrm{T}_{\mathrm{H}} 1$ responses and/or TLR activity [14]. This may be compatible with the observed ability of MCT to enhance CTL responses, which Alum failed to do. Further work will be required to elucidate the mechanism of this difference, as both Alum and MCT form a depot and may activate the inflammasome pathway. An obvious hypothesis is that Alum induces a $\mathrm{T}_{\mathrm{H}} 2$ driving pathway in addition to the inflammasome or vice versa, MCT may activate a $\mathrm{T}_{\mathrm{H}} 1$ driving pathway. The distinctions portrayed in their respective immunological profiles are also likely to be be partly governed by their inherent formulation/structural characteristics (i.e. particle size, morphology, antigen adsorption etc). In addition to this, it is known that tryptophan or arginine serve as direct immune-modulators, a possibility that has not been extensively studied for tyrosine $[48,49]$.

Taken together, this study shows that MCT is a potent enhancer of CTL responses and may be viewed as a multi-purpose adjuvant with novel indications. As such, its effectiveness and compatibility in a mix- and match adjuvant systems approach should be further tested in preclinical and human immunotherapy trials. Combination of MCT with nanoparticles appears particularly attractive, as the micron-sized adjuvants will form a local depot at the injection site with concomitant activation of skin-resident antigen-presenting cells. Nanoparticles will be released over time, draining to local LNs for extended time-periods, causing an optimal immune reaction. Thus, the combination of nanoparticles with micronsized adjuvants may optimally harness the properties of the lymphatic system.

\section{Additional files}

Additional file 1: Movie S1. showing AF488 CuMV T-VLPs decorating the surface of microcrystalline tyrosine crystals MCT adjuvant. (MP4 $13481 \mathrm{~kb}$ )

Additional file 2: Movie S2 showing the popliteal LN $24 \mathrm{~h}$ after injecting CuMV T-p33 nano-vaccine in mice footpad. (MP4 19763 kb)
Additional file 3: Movie S3. showing the popliteal LN $24 \mathrm{~h}$ after injecting CUMV TT-p33 nano-vaccine formulated with MCT adjuvant in mice footpad. (MP4 $12060 \mathrm{~kb}$ )

Additional file 4: Movie S4 showing the popliteal LN $216 \mathrm{~h}$ after injecting CuMV ${ }_{\pi}$-p33 nano-vaccine in mice footpad. (MP4 30385 kb)

Additional file 5: Movie S5 showing the popliteal LN $216 \mathrm{~h}$ after injecting CuMV T-p33 nano-vaccine formulated with MCT adjuvant in mice footpad. (MP4 $34519 \mathrm{~kb}$ )

\section{Acknowledgments}

None.

\section{Funding}

This work was supported by Bencard Adjuvant Systems, Dominion Way, UK, the Swiss Cancer League (KFS-4132-02-2017) and Qatar Foundation.

Availability of data and materials

Data are available in the main text and supplementary materials, raw data available upon request by the correspondent author.

\section{Authors' contributions}

Design of experiments, acquisition of data, interpretation of data, analysis of data: MOM, MDH, GCM, MV, CR, DS, ER, DS and MFB; VLPs expression and production: $\mathrm{CL}, \mathrm{AZ}$; Confocal microscopy imaging and stereomicroscopic imaging: MS, ER, PE and JVS. Writing, revise and revision of manuscript: MOM, TMK, AK, DS, MV, MAS, MFK and MFB. Technical and material support: MOM, MDH, DS, LZ, AK and MFB. Study supervision: MFB. All authors read and approved the final manuscript.

\section{Ethics approval}

All procedures on animals were conducted at University of Bern in accordance with the Swiss Animals Act (455.109.1) (September 2008, 5th) University of Bern.

\section{Consent for publication}

Not applicable.

\section{Competing interests}

The authors declare that they have no competing interests. Martin Bachmann and Mona Mohsen own shares of DeepVax $\mathrm{GmbH}$ involved in developing virus-like particles based vaccines for cancer, other authors declare that they have no competing interests.

\section{Publisher's Note}

Springer Nature remains neutral with regard to jurisdictional claims in published maps and institutional affiliations.

\section{Author details}

'Jenner Institute, Nuffield Department of Medicine, University of Oxford, Oxford, UK. ²Department of BioMedical Research, Immunology RIA, Inselspital, University of Bern, Bern, Switzerland. ${ }^{3}$ Bencard Adjuvant Systems, Dominion Way, Worthing, UK. ${ }^{4}$ Latvian Biomedical Research \& Study Centre, Riga, Latvia. ${ }^{5}$ Institute of anatomy, University of Bern, Bern, Switzerland.

${ }^{6}$ Theodor Kocher Institute, University of Bern, Bern, Switzerland. ${ }^{7}$ Department of Medical Oncology, Bern University Hospital, University of Bern, Bern, Switzerland. ${ }^{8}$ International Immunology Center, Anhui Agricultural University, Hefei, Anhui, China. ${ }^{9}$ Department of dermatology, University of Zurich, Zurich, Switzerland. ${ }^{10}$ Department of Oncology, University of Lausanne, Lausanne, Switzerland. ${ }^{11}$ National Center for Cancer Care \& Research (NCCCR), Doha, State of Qatar.

Received: 13 November 2018 Accepted: 2 April 2019 Published online: 26 April 2019

\section{References}

1. Hu Z, Ott PA, Wu CJ. Towards personalized, tumour-specific, therapeutic vaccines for cancer. Nat Rev Immunol. 2017;18(3):168-182.

2. Lebel ME, Chartrand K, Leclerc D, Lamarre A. Plant viruses as nanoparticlebased vaccines and adjuvants. Vaccines (Basel). 2015;3(3):620-37. 
3. Piazzolla G, Nuzzaci M, Tortorella C, Panella E, Natilla A, Boscia D, et al. Immunogenic properties of a chimeric plant virus expressing a hepatitis $C$ virus (HCV)-derived epitope: new prospects for an HCV vaccine. J Clin Immunol. 2005;25(2):142-52.

4. Nuzzaci M, Piazzolla G, Vitti A, Lapelosa M, Tortorella C, Stella I, et al. Cucumber mosaic virus as a presentation system for a double hepatitis $C$ virus-derived epitope. Arch Virol. 2007;152(5):915-28.

5. Zeltins A, West J, Zabel F, El Turabi A, Balke I, Haas S, et al. Incorporation of tetanus-epitope into virus-like particles achieves vaccine responses even in older recipients in models of psoriasis, Alzheimer's and cat allergy. NPJ Vaccines. 2017;2:30.

6. Fettelschoss-Gabriel A, Fettelschoss V, Thoms F, Giese C, Daniel M, Olomski $F$, et al. Treating insect-bite hypersensitivity in horses with active vaccination against IL-5. J Allergy Clin Immunol. 2018

7. Bachmann MF, Zeltins A, Kalnins G, Balke I, Fischer N, Rostaher A, et al. Vaccination against IL-31 for the treatment of atopic dermatitis in dogs. J Allergy Clin Immunol. 2018.

8. Cox JC, Coulter AR. Adjuvants - a classification and review of their modes of action. Vaccine. 1997;15(3):248-56.

9. Bastola R, Noh G, Keum T, Bashyal S, Seo JE, Choi J, et al. Vaccine adjuvants: smart components to boost the immune system. Arch Pharm Res. 2017:40(11):1238-48.

10. Klimek L, Schmidt-Weber CB, Kramer MF, Skinner MA, Heath MD. Clinical use of adjuvants in allergen-immunotherapy. Expert Rev Clin Immunol. 2017;13(6):599-610.

11. Leuthard DS, Duda A, Freiberger SN, Weiss S, Dommann I, Fenini G, et al. Microcrystalline tyrosine and aluminum as adjuvants in allergen-specific immunotherapy protect from lgE-mediated reactivity in mouse models and act independently of Inflammasome and TLR signaling. J Immunol. 2018; 200(9):3151-9.

12. Wheeler AW, Moran DM, Robins BE. Driscoll A. I-Tyrosine as an immunological adjuvant. Int Arch Allergy Appl Immunol. 1982;69(2):113-9.

13. Heath MD, Swan NJ, Marriott AC, Silman NJ, Hallis B, Prevosto C, et al. Comparison of a novel microcrystalline tyrosine adjuvant with aluminium hydroxide for enhancing vaccination against seasonal influenza. BMC Infect Dis. 2017;17(1):232.

14. Cabral-Miranda G, Heath MD, Mohsen MO, Gomes AC, Engeroff P, Flaxman A, et al. Virus-like particle (VLP) plus microcrystalline tyrosine (MCT) adjuvants enhance vaccine efficacy improving $T$ and $B$ cell immunogenicity and protection against Plasmodium berghei/vivax. Vaccines (Basel). 2017;5(2).

15. Wheeler AW, Marshall JS, Ulrich J. A Th1-inducing adjuvant, MPL, enhances antibody profiles in experimental animals suggesting it has the potential to improve the efficacy of allergy vaccines. Int Arch Allergy Immunol. 2001;126(2):135-9.

16. Worm M, Higenbottam T, Pfaar O, Mosges R, Aberer W, Gunawardena K, et al. Randomized controlled trials define shape of dose response for Pollinex Quattro birch allergoid immunotherapy. Allergy. 2018;73(9):1812-22.

17. Cabral-Miranda G, Heath MD, Gomes AC, Mohsen MO, Montoya-Diaz E, Salman AM, et al. Microcrystalline tyrosine (MCT((R))): a depot adjuvant in licensed allergy immunotherapy offers new opportunities in malaria. Vaccines (Basel). 2017;5(4).

18. Mempel TR, Henrickson SE, Von Andrian UH. T-cell priming by dendritic cells in lymph nodes occurs in three distinct phases. Nature. 2004;427(6970):154-9.

19. Tainaka K, Kubota SI, Suyama TQ, Susaki EA, Perrin D, Ukai-Tadenuma M, et al. Whole-body imaging with single-cell resolution by tissue decolorization. Cell. 2014;159(4):911-24.

20. Mohsen MO, Gomes AC, Cabral-Miranda G, Krueger CC, Leoratti FM, Stein $J V$, et al. Delivering adjuvants and antigens in separate nanoparticles eliminates the need of physical linkage for effective vaccination. J Control Release. 2017;251:92-100.

21. Rahbar M, Naraghi ZS, Mardanpour M, Mardanpour N. Tumor-infiltrating CD8+ lymphocytes effect on clinical outcome of Muco-cutaneous melanoma. Indian J Dermatol. 2015;60(2):212.

22. Mihm MC Jr, Mule JJ. Reflections on the histopathology of tumor-infiltrating lymphocytes in melanoma and the host immune response. Cancer Immunol Res. 2015:3(8):827-35.

23. Ambuhl PM, Tissot AC, Fulurija A, Maurer P, Nussberger J, Sabat R, et al. A vaccine for hypertension based on virus-like particles: preclinical efficacy and phase I safety and immunogenicity. J Hypertens. 2007;25(1):63-72.

24. Tissot AC, Maurer P, Nussberger J, Sabat R, Pfister T, Ignatenko S, et al. Effect of immunisation against angiotensin II with CYT006-AngQb on ambulatory blood pressure: a double-blind, randomised, placebo-controlled phase lla study. Lancet. 2008;371(9615):821-7.
25. Cavelti-Weder C, Timper K, Seelig E, Keller C, Osranek M, Lassing U, et al. Development of an interleukin-1 beta vaccine in patients with type 2 diabetes. Mol Ther. 2016;24(5):1003-12.

26. Baskin JM, Prescher JA, Laughlin ST, Agard NJ, Chang PV, Miller IA, et al. Copper-free click chemistry for dynamic in vivo imaging. Proc Natl Acad Sci U S A. 2007:104(43):16793-7.

27. Chang PV, Prescher JA, Sletten EM, Baskin JM, Miller IA, Agard NJ, et al. Copper-free click chemistry in living animals. Proc Natl Acad Sci U S A. 2010;107(5):1821-6.

28. Mohsen MO, Zha L, Cabral-Miranda G, Bachmann MF. Major findings and recent advances in virus-like particle (VLP)-based vaccines. Semin Immunol. 2017:34:123-32.

29. Koster BD, van den Hout M, Sluijter BJR, Molenkamp BG, Vuylsteke R, Baars A, et al. Local adjuvant treatment with low-dose CpG-B offers durable protection against disease recurrence in clinical stage I-II melanoma: data from two randomized phase II trials. Clin Cancer Res. 2017:23(19):5679-86.

30. Lai C, Duan S, Ye F, Hou X, Li X, Zhao J, et al. The enhanced antitumorspecific immune response with mannose- and $\mathrm{CpG-ODN-coated} \mathrm{liposomes}$ delivering TRP2 peptide. Theranostics. 2018;8(6):1723-39.

31. Kakwere H, Ingham ES, Allen R, Mahakian LM, Tam SM, Zhang $H$, et al. Toward personalized peptide-based Cancer Nanovaccines: a facile and versatile synthetic approach. Bioconjug Chem. 2017;28(11):2756-71.

32. Baumgaertner $\mathrm{P}$, Costa Nunes $\mathrm{C}$, Cachot A, Maby-El Haijami H, Cagnon L, Braun $M$, et al. Vaccination of stage III/IV melanoma patients with long NYESO-1 peptide and CpG-B elicits robust CD8(+) and CD4(+) T-cell responses with multiple specificities including a novel DR7-restricted epitope. Oncoimmunology. 2016:5(10):e1216290.

33. Speiser DE, Lienard D, Rufer N, Rubio-Godoy V, Rimoldi D, Lejeune F, et al. Rapid and strong human CD8+ T cell responses to vaccination with peptide, IFA, and CpG oligodeoxynucleotide 7909. J Clin Invest. 2005;115(3):739-46.

34. Sparwasser T, Hultner L, Koch ES, Luz A, Lipford GB, Wagner H. Immunostimulatory $\mathrm{CpG}$-oligodeoxynucleotides cause extramedullary murine hemopoiesis. J Immunol. 1999;162(4):2368-74.

35. Sparwasser T, Miethke T, Lipford G, Borschert K, Hacker H, Heeg K, et al. Bacterial DNA causes septic shock. Nature. 1997;386(6623):336-7.

36. Storni T, Ruedl C, Schwarz K, Schwendener RA, Renner WA, Bachmann MF. Nonmethylated CG motifs packaged into virus-like particles induce protective cytotoxic T cell responses in the absence of systemic side effects. J Immunol. 2004;172(3):1777-85.

37. Goldinger SM, Dummer R, Baumgaertner P, Mihic-Probst D, Schwarz K, Hammann-Haenni A, et al. Nano-particle vaccination combined with TLR-7 and -9 ligands triggers memory and effector CD8(+) T-cell responses in melanoma patients. Eur J Immunol. 2012;42(11):3049-61.

38. Krieg AM. Therapeutic potential of toll-like receptor 9 activation. Nat Rev Drug Discov. 2006;5(6):471-84

39. Bachmann MF, Jennings GT. Vaccine delivery: a matter of size, geometry, kinetics and molecular patterns. Nat Rev Immunol. 2010:10(11):787-96.

40. Hailemichael Y, Dai ZM, Jaffarzad N, Ye Y, Medina MA, Huang XF, et al. Persistent antigen at vaccination sites induces tumor-specific CD8(+) T cell sequestration, dysfunction and deletion. Nat Med. 2013;19(4):465.

41. Stills HF Jr. Adjuvants and antibody production: dispelling the myths associated with Freund's complete and other adjuvants. ILAR J. 2005;46(3):280-93.

42. Ammi R, De Waele J, Willemen Y, Van Brussel I, Schrijvers DM, Lion E, et al. Poly(l:C) as cancer vaccine adjuvant: knocking on the door of medical breakthroughs. Pharmacol Ther. 2015;146:120-31.

43. O'Hagan DT, Friedland LR, Hanon E, Didierlaurent AM. Towards an evidence based approach for the development of adjuvanted vaccines. Curr Opin Immunol. 2017:47:93-102.

44. Temizoz B, Kuroda E, Ishii KJ. Vaccine adjuvants as potential cancer immunotherapeutics. Int Immunol. 2016:28(7):329-38.

45. Brewer KD, Weir GM, Dude I, Davis C, Parsons C, Penwell A, et al. Unique depot formed by an oil based vaccine facilitates active antigen uptake and provides effective tumour control. J Biomed Sci. 2018;25(1):7.

46. Khong H, Overwijk WW. Adjuvants for peptide-based cancer vaccines. J Immunother Cancer. 2016:4:56.

47. Lee N, Zakka LR, Mihm MC Jr, Schatton T. Tumour-infiltrating lymphocytes in melanoma prognosis and cancer immunotherapy. Pathology. 2016;48(2):177-87.

48. Mellor AL, Lemos H, Huang L. Indoleamine 2,3-dioxygenase and tolerance: where are we now? Front Immunol. 2017:8:1360

49. Rath M, Muller I, Kropf P, Closs El, Munder M. Metabolism via arginase or nitric oxide synthase: two competing arginine pathways in macrophages. Front Immunol. 2014;5:532 